This item was submitted to Loughborough's Research Repository by the author.

Items in Figshare are protected by copyright, with all rights reserved, unless otherwise indicated.

\title{
Dealing with the distress of people with intellectual disabilities reporting sexual assault and rape
}

PLEASE CITE THE PUBLISHED VERSION

http://dx.doi.org/10.1177/1461445615578962

PUBLISHER

SAGE Publications / ( T) The Author(s)

VERSION

AM (Accepted Manuscript)

\section{PUBLISHER STATEMENT}

This work is made available according to the conditions of the Creative Commons Attribution-NonCommercialNoDerivatives 4.0 International (CC BY-NC-ND 4.0) licence. Full details of this licence are available at: https://creativecommons.org/licenses/by-nc-nd/4.0/

\section{LICENCE}

CC BY-NC-ND 4.0

\section{REPOSITORY RECORD}

Antaki, Charles, Emma Richardson, Elizabeth Stokoe, and Sara Willott. 2019. "Dealing with the Distress of People with Intellectual Disabilities Reporting Sexual Assault and Rape". figshare.

https://hdl.handle.net/2134/18113. 
Dealing with the distress of people with intellectual disabilities reporting sexual assault and rape

Charles Antaki*, Emma Richardson, Elizabeth Stokoe

Dept of Social Sciences

Loughborough University

Loughborough

LE11 3TU

UK

To appear in Discourse Studies, 2015, vol 17 pp xx-xx

and

Sara Willott

Birmingham Community HealthCare NHS Trust

Learning Disability, Psychology Services

The Greenfields, 30 Brookfield Road

Kings Norton

Birmingham B30 3QY

UK

\section{Abstract}

When police officers interview people with intellectual disabilities who allege sexual assault and rape, they must establish rapport with the interviewee, but deal with their distress in a way that does not compromise the interview's impartiality and its acceptability in court. Inspection of 19 videotaped interviews from an English police force's records reveals that the officers deal with expressed distress by choosing among three practices: minimal (e.g. okay) or no acknowledgement; acknowledging the expressed emotion as a matter of the complainant's difficulty in proceeding (e.g. take your time); and, rarely (and only if the complainant were apparently unable to resume their talk) explicit reference to their emotion (e.g. it's obviously upsetting for you). We discuss these practices as ways of managing the conflicting demands of rapport and evidencegathering.

* corresponding author. E mail address: c.antaki@Lboro.ac.uk

Short title: Dealing with distress in police interviews 
Acknowledgement: We are grateful for the help and advice of personnel in the regional police force with whom we collaborated, who must remain anonymous. We would also like to thank Chris Pudlinksi and Val Williams for insightful comments on a draft of this article. 
Dealing with the distress of people with intellectual disabilities reporting sexual assault and rape

Police investigations of sexual assault and rape inevitably require the alleged victim to revisit their experiences in interview, and be subjected to detailed probing. This may be distressing. Our interest in this article is to examine how police interviewers deal with the distress of one particular group of such alleged victims, that is, people with an intellectual disability, whose cognitive powers are likely to be uncomfortably tested by the requirements of a formal police interview.

People with intellectual disabilities are more likely to be sexually abused (McEachern, 2012) and sexually assaulted (Petersilia, 2001) than people without such disabilities. They are likely in consequence to suffer "marked increases in the frequency and severity of emotional, physiological and behavioural symptoms of psychological distress" according to Rowsell, Clare and Murphy (2013, p 257). They are however less likely to speak out about the abuse, and the number of victims pursuing alleged offenders through the criminal justice system is a tiny fraction of those abused (Brown et al, 1995, for example, estimate 6\%). For those who do bring a complaint, the legal process can cause them emotional and psychological distress as they re-live the incident. Indeed, research suggests that adult rape victims with learning disabilities or psychiatric problems are over-represented in terms of cases that drop out of the system (Lea et al., 2003).

One element in the complex of reasons for the failure of sexual assault cases involving adults with ID may be their experiences with the criminal justice system at an early stage of the investigation. In this article we use a sample of videotapes collected from an English police force to examine the way the police handle the complainant's first recorded interview. This interview is a crucial part of the police's decision as to whether to proceed with the case. It requires the 
police interviewer to solicit a description of events, in forensic detail, to assess whether (a) a crime has been committed; (b) there is enough evidence to pursue an investigation and locate the perpetrator; and (c) the complainant's account specifically its reliability and plausibility - would stand up in court. In so doing, the officer will ask for detailed descriptions of the complainant's experiences, and, if necessary, probe and challenge apparent inconsistencies or vagueness. The intrusive and intimate nature of the information being solicited (involving explicit description of genitalia) would risk causing discomfort to any complainant; where the complainant has difficulty in understanding questions and in expressing themselves - as people with ID do - the risk of frustration and distress may be magnified.

The difficulties that people with ID have in police interviews (mostly as suspects) has been much researched since the pioneering work of Clare and Gudjonsson (1993) and a useful summary is provided in a recent report by the Royal College of Psychiatrists (2014). The report notes that police and other members of the legal profession systematically have failed to acknowledge people with ID's tendency to acquiesce; their deficiencies in vocabulary; their tendency to report apparent contradictions; and their memory limitations. One of the recommendations of the report is that "all police officers, in particular custody officers and community support officers, need to have intellectual disability awareness training as part of their induction process. This training should be provided with input from health professionals" (2014 p. 11).

The main instrument for such training and guidance given to police interviewers in England and Wales is set out in Achieving Best Evidence in Criminal Proceedings: Guidance on interviewing victims and witnesses, and guidance on using special measures (henceforth $A B E$ ) published by the Ministry of Justice (2011). These guidelines mandate that the interviewer develop a rapport with the interviewee. This extract from the guidelines gives a clear instruction:

2.230 Some witnesses may be unhappy or feel shame or resentment about being questioned, especially on personal 
matters. In the rapport phase, and throughout the interview, the interviewer should convey to the witness that they have respect and sympathy for how the witness feels. $(A B E, 2011$, p. 66)

But the guidelines also remind the interviewer that this is an interview in the service of a possible court case:

3.1 The basic goal of an interview with a witness is to obtain an accurate and reliable account in a way which is fair, is in the witness's interests and is acceptable to the court. (ABE, 2011, $\mathrm{p}$ 68)

This overarching mandate requires the interviewer to ensure that that they are seen to be impartial, so as to collect evidence as free as possible from any implication of influence. It is important to note that were the case to come to court, the tape of the interview would be made available to counsel defending the alleged perpetrator, who would free to call for any part of it to be played in court; hence the need for the information solicited from the complainant to be seen to be uncontaminated by the interviewer's behaviour. There is, then, something of a conflict between the need for rapport, and the imperative to obtain full and accurate information without the taint of partiality.

Some institutional ways of dealing with distress weigh the balance towards empathy . Call-takers on a peer-run "warm" helpline, for example, will offer explicit support to callers as definitional part of the service the offer (Pudlinski, 2005). Other institutional objectives point the other way. When there is a tension between expressing empathy and progressing the institutional task in hand, the interactional research literature on dealing with clients suggests that many practitioners - for example, medical professionals (Heritage and Lindström, 2012, Ruusuvuori 2005) - will put non-emotion-oriented tasks first, and avoid offering encouraging receipts to expressions of trouble or distress. This may be so even when the troubles being reported are obviously highly upsetting. 
Hepburn and Potter (2007) find that, when NSPCC ${ }^{1}$ call-takers hear reports of child neglect and abuse, "full scale surprise at the abuse, explicit condemnation of the perpetrator, and overt sympathy for either victim or reporter are unusual. Instead, abuse reports are typically followed by actions that perform institutional tasks - for example, evidence gathering or advising" (2007, p 100). Given the evidence-gathering objectives of the police interview, police interviewers are very likely to respond as NSPCC call-takers do. But the further legal obligations they work under (their need to be seen to be impartial, and to test the complainant's accounts against forensic standards of proof) may constrain them still more closely, and make the pattern that Hepburn and Potter (2007) identify even more pronounced. What is of interest is how it is brought off while maintaining the "respect and sympathy" for the complainant that the national police guidelines require.

\section{DATA AND METHOD}

Our data come from a police force in England, who provided us with 20 videotapes of, and summary information about, interviews from archived cases involving complainants with intellectual disabilities. The selection of these cases was made by local personnel, on their judgement that they were representative of such complainants. The interviews were recorded between 2010 and 2013, in one city station, by trained officers. Interviews lasted between 21 minutes and just over 2 hours. The tapes were visually and aurally anonymised before leaving the police station. We excluded from analysis one tape which was incomplete. of the 19 cases, dealt with 10 alleged rape and the rest sexual assault. Internal evidence from the tapes showed that two of the complainants were children under 16 (a boy and a girl); 14 were young women; one was a mature woman; and two were men (one young and one young-middle aged ). Three of the cases led to a court case, two resulting in a guilty verdict. The other 17 led to no further action.

\footnotetext{
${ }^{1}$ The National Society for the Prevention of Cruelty to Children, a UK charity which operates a help-line for callers to report abuse.
} 
Description of the environment of the interview

Once a case is brought to the attention of the police by the person alleging assault, or someone acting on their behalf, basic details are recorded, an officer is assigned to the case and the alleged victim is invited for interview. Before this interview, the officer may or may not investigate the matter further. In the case of complainants suspected of being, or known to be, intellectual disabled, steps may be taken to identify the nature of their disability (for example, by consultation with educational, medical or social work authorities). At the station from which our cases come, such information is recorded only briefly (e.g. "Learning disability, attends special school").

On the day of the interview, at the station, the complainant (and any accompanying friend or relative, carer, social worker, or other professional) is met by the assigned officer who, before the interview proper, engages them in a preliminary conversation. This will typically be short and neutral, and would normally serve as an opportunity for the officer to alert the interviewee to the nature of the upcoming discussion as an official one which will be recorded for use in court (should the matter proceed). The complainant's party is then shown the lay-out of the interview room and the observation room, and the cameras are located and explained. A companion (e.g. a relative or case worker) may be present in the interview room, but take no part in the conversation.

To examine the interviews for the way in which distress is dealt with, we shall use Conversation Analysis (CA) (for an overview, see the collection in Sidnell and Stivers, 2012), which, building on a base established in ordinary conversation, has been used extensively in research on how practitioners deliver their services in a wide variety of environments where clients may present accounts of troubles - recent overviews can be found of primary medical care (Robinson and Heritage, 2014); welfare services (Drew et al, 2014); police and mediation interviews (Stokoe, 2014); and telephone helplines (Hepburn et al, 2014). We shall use CA here to identify the sequential locations in which distress appears, and identify the interactional formats with which specific interviewers deal with 
it, juggling the need for rapport on the one hand and the requirement for dispassionate evidence-gathering on the other.

\section{ANALYSIS}

Inspection of the tapes revealed that the interview fell, as mandated by the national guidelines Achieving Best Evidence, into four phases: an orientation phase, in which the purpose, organisation and recording of the interview is explained; a free-narrative phase in which the complainant recounts their experiences; a probing phase (which usually takes up the bulk of the interview) in which the interviewer solicits detail and checks inconsistencies and other snags in the account; and a final closing phase. Distress emerged in the narrative and the probing phase.

\section{Reports of distress.}

We distinguished between two senses of distress: reports of distress, where the complainant described how they had felt at the time of the incident, or how they were currently feeling in general; and distress expressed in the moment (by crying, whimpering, holding their head in the hands, moaning, and so on). Our main analysis is of this latter kind. But it is worth briefly mentioning that when the former kind - reports of distress - appeared in the complainant's narrative or in response to questions, they were received by the interviewing officer only with minimal, or sometimes no, acknowledgement. Examples of such reports of past distress and the interviewers' responses are shown in Extracts 1 and $2^{2}$.

\section{Extract 1. INT 9 line 157. Scared.}

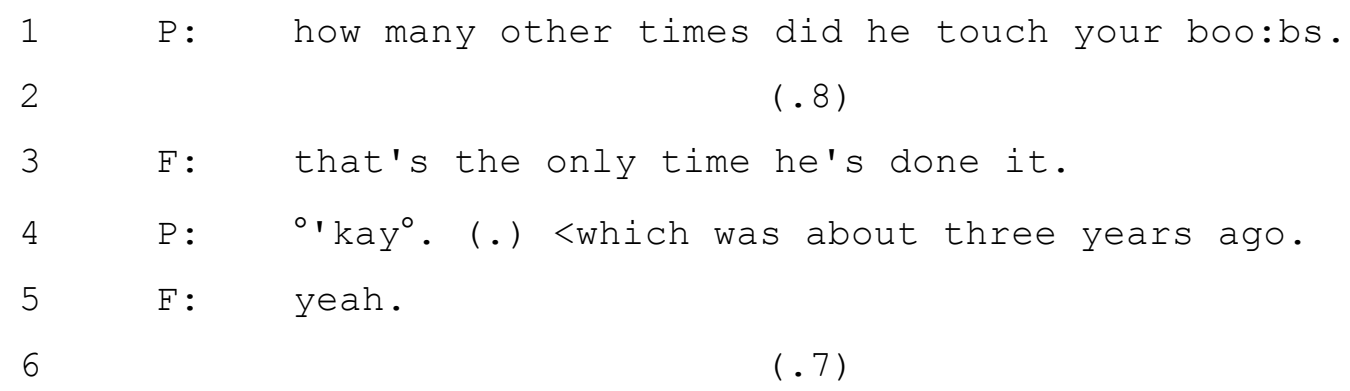

${ }^{2}$ In this and all extracts, "P" is the interviewing police officer, and "F" or "M" denotes the gender of the interviewee. 


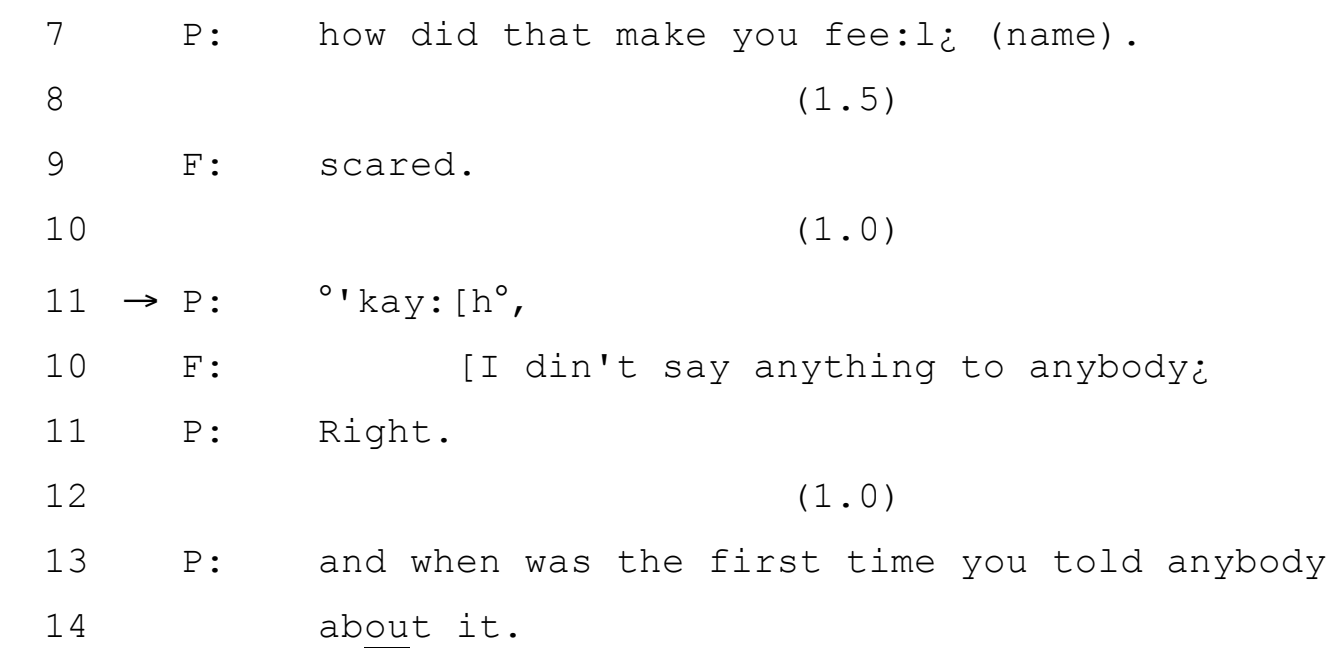

In the extract above, the complainant's report that she felt scared (line 9) is met with a second of silence, then a quiet okay from the interviewer. The interviewer may have been going on to give a more elaborate reply, but the complainant adds, in overlap to the outbreath at the very end of okay, a further element to the story; this too is only minimally receipted.

Extract 2.INT20 line 414: Pee off.

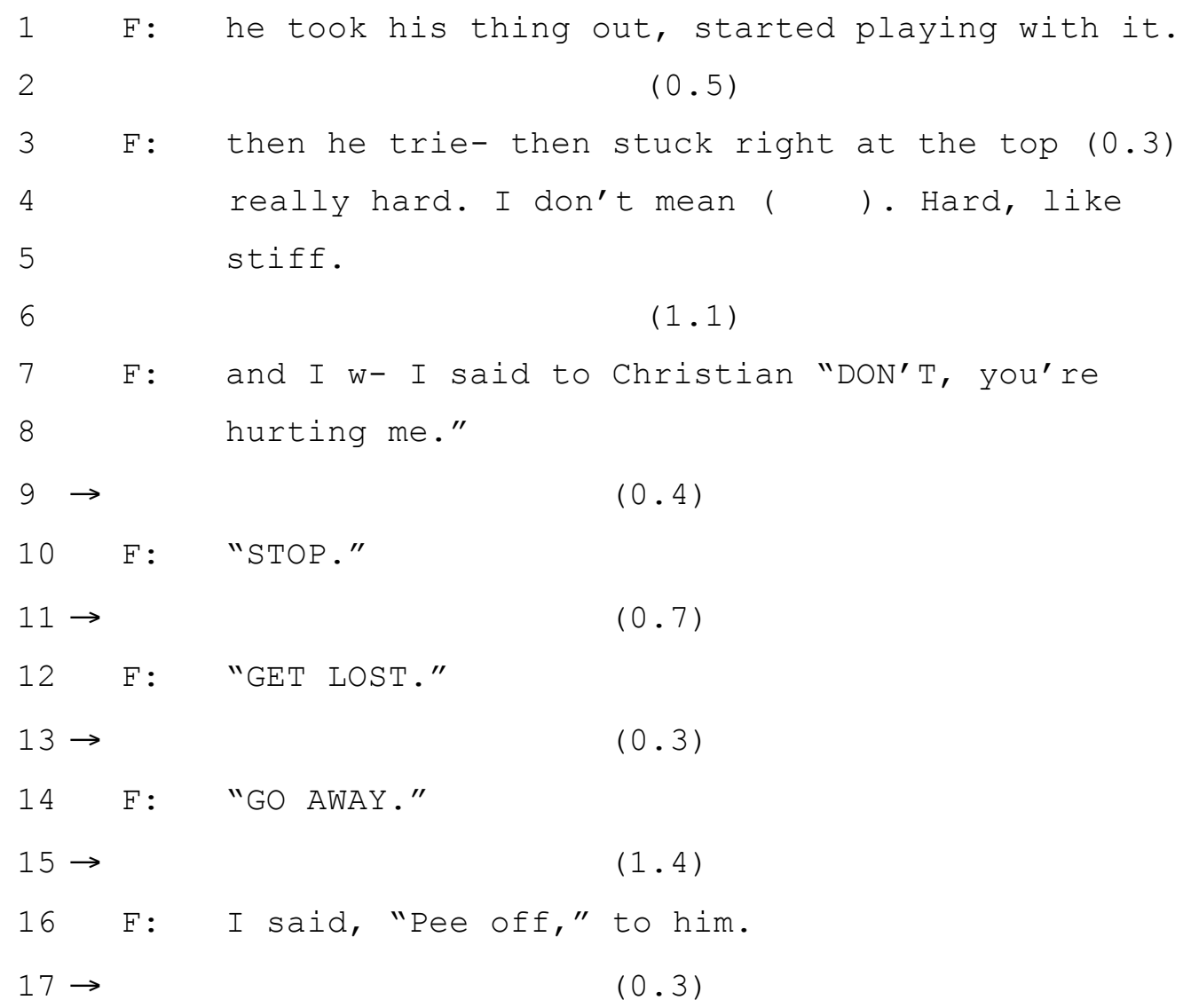




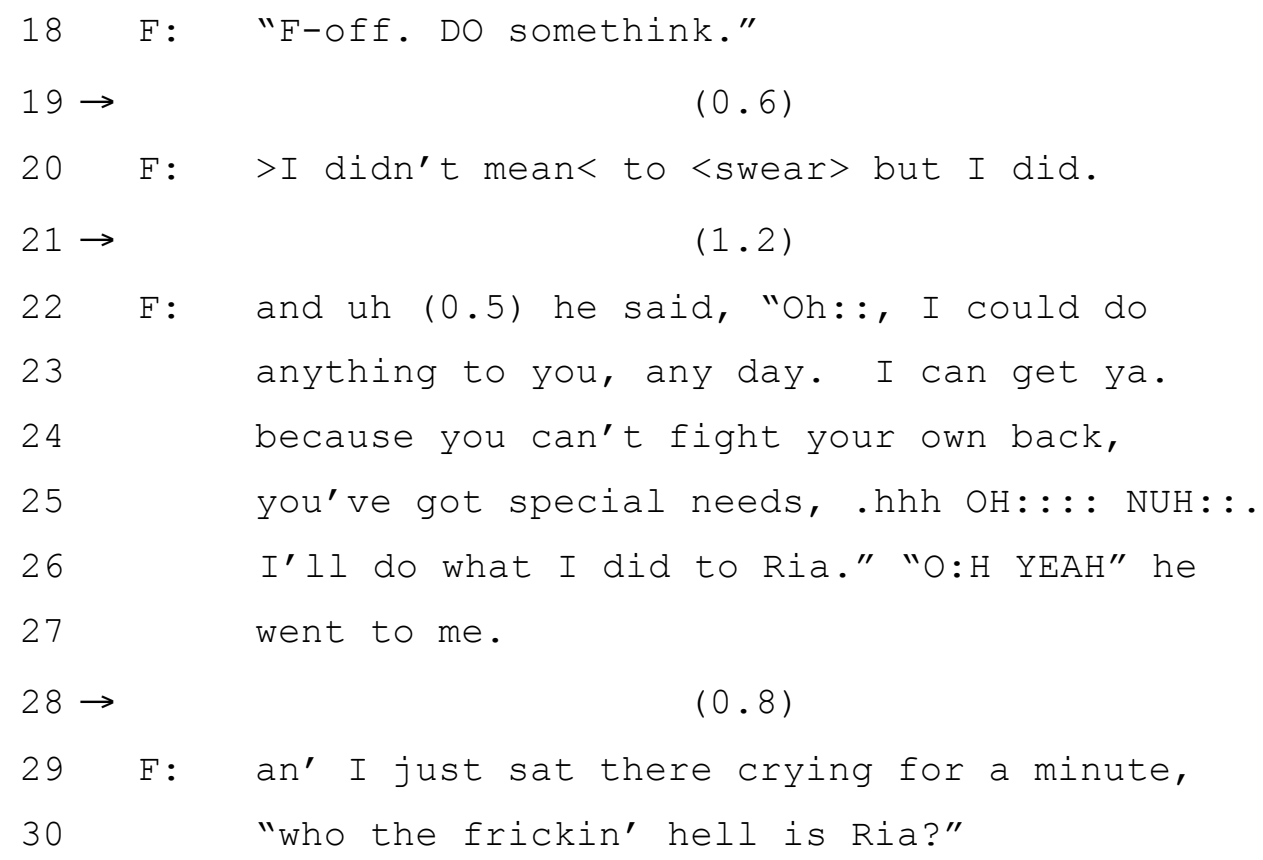

Note that in Extract 2, the arrows indicate the multiple occasions at which the interviewer could have taken a turn at talk to acknowledge the complainant's reported distress, but does not do so (and the video, although it does not the capture the interviewer's face, shows no obvious nodding or other head movement). The reports of distress are treated as being part of the "narrative world" being described in the complainant's account. The emotion described in the story is probably better conceived of as an economical way for the teller to display her contemporaneous stance towards the events (for emotion as stance, see M. H. Goodwin et al, 2012). In receiving the account, the interviewer is cooperating by aligning (Lindström and Sorjonen, 2013) with the activity of storytelling, but not affiliating (Lindström and Sorjonen, 2013) with the stance expressed in it.

Extract 3, below, is a combination of both kinds of reported distress. It shows the interviewer's non-response both to the complainant's report of her current feelings of shame, and her report of the fear and upset she felt at the time of the assault.

Extract 3. INT13 Shame and upset. Note that the $\sim$ sign in line 24 indicates "wobbly voice" 


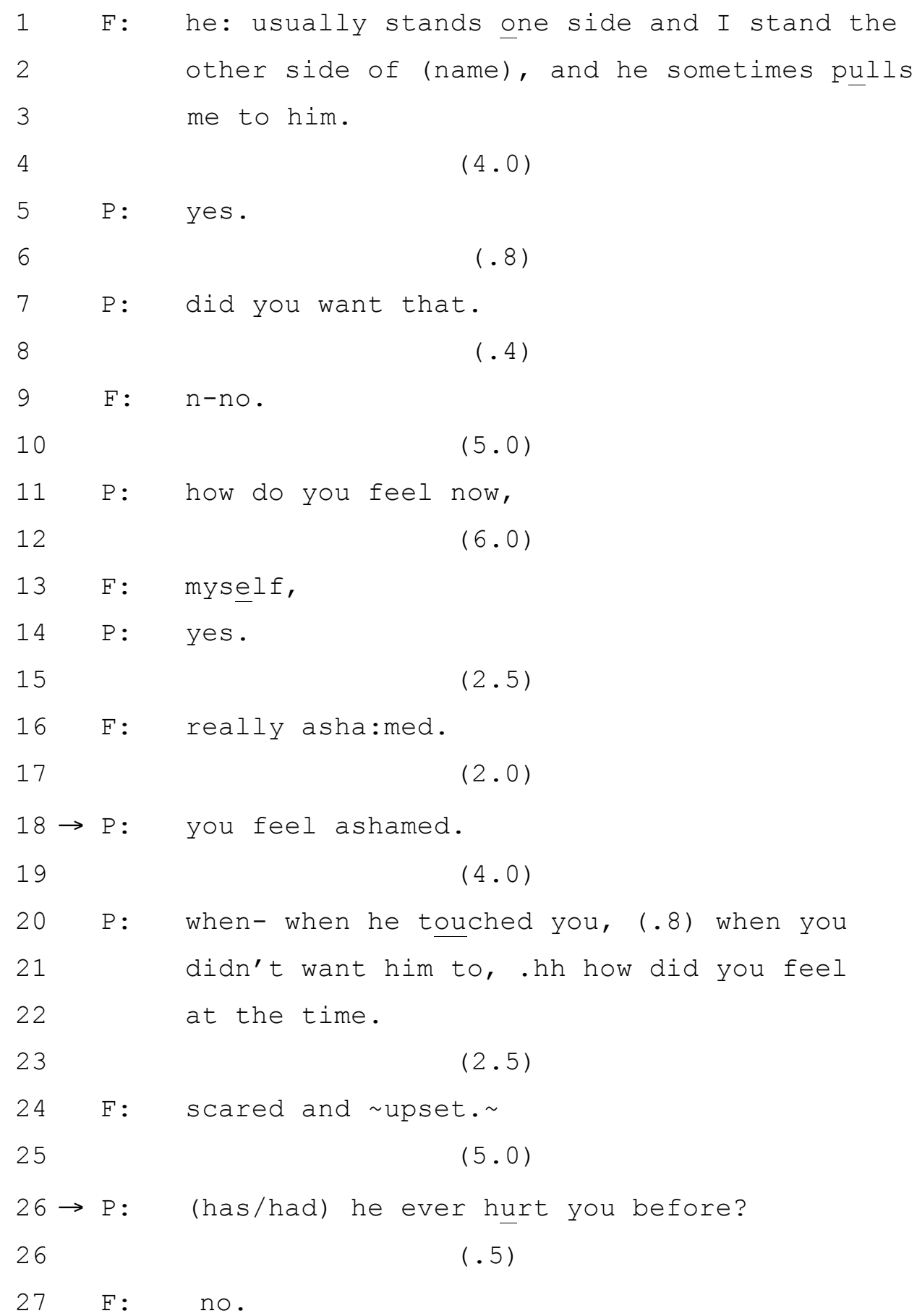

In the extract above, the interviewer at line 18 receipts the complainant's report of current feelings of shame by an repeat response-confirmation (and deleting the amplifying adjective really). Such repeats are common in institutional questioning such as classroom exchanges (Park, 2014): when delivered without rising intonation, they serve to affirm that the response has been heard. Without further elaboration, it withholds an appreciation of the content - here, of the emotion that the answer expresses. At line 21-22 the interviewer asks the 
complainant how she felt at the time. The complainant's answer has a "wobbly" quality, implying incipient crying (Hepburn, 2004). However, the interviewer responds with silence and an immediate move to a follow-up question making no reference to the emotions reported as such. In sum: the reports of distress here, as in Extracts 1 and 2, are treated as part of a dispassionate account-for-therecord, and not as warranting acknowledgement of the emotional content as such. In effect, the format of the exchange is like that of the medical encounter where, as Maynard and Heritage (2005) put it, practitioners "design their questions so as to display a neutral stance toward the lifestyle matter at issue" (2005, p. 433) and maintain that neutrality in the face of reports of distressing conditions.

\section{Distress displayed in the moment}

Before examining what happens in our data, it is worth noting how an expression of in-the-moment distress, (e.g. crying or incipient crying, whimpering, holding the head in the hands, moaning, and so on) might be responded to when the interlocutor is free of institutional constraints. In this example, taken from Hepburn and Potter (2012), two friends are on the phone. Jill is apparently upset by something that happened at the weekend, and we join as Kerry probes the trouble.

Extract 4. (From Hepburn and Potter, 2012, p, 201-202, notation slightly simplified). Note that the \# sign in line 6 indicates "creaky voice".

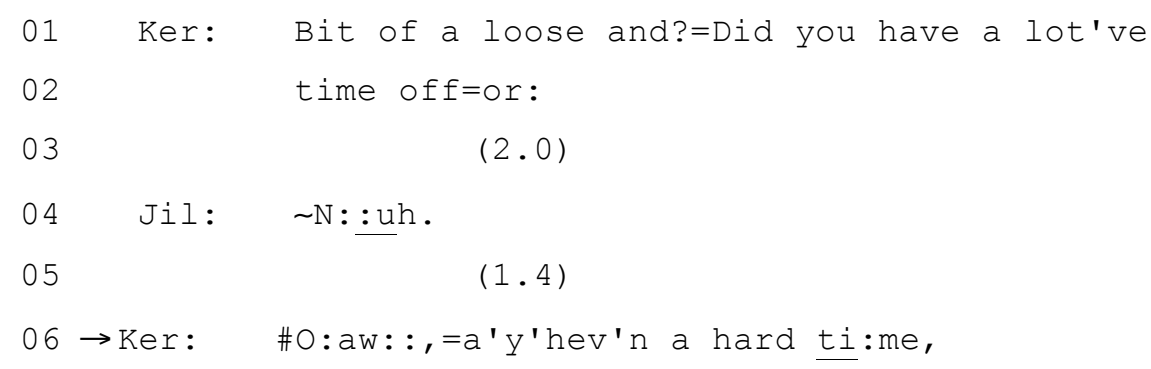

At line 4, Jill's "wobbly voice" "no" is (especially given the preceding signs, not shown here) allows the fairly confident inference that she is currently feeling some kind of emotional upset. Note Kerry's response. As Hepburn and Potter say, her use, in the arrowed line, of a "creaky" and prosodically drawn-out change-of- 
state token "oh" (Heritage, 1984) and a yes/no question projecting Jill's agreement that she was "having a bad time", makes us hear the response as warmly sympathetic, encouraging Jill to expand on her troubles. This, of course, is in a non-institutional conversation, between friends.

In our police data it was apparent that the kind of visible distress that Jill was displaying in Example 4 was not common to all the interviews, despite the nature of the events that the complainant was describing (of the 19 cases, distress was only manifested unambiguously in six cases, and more ambiguously in two more). However, in all these cases there was a fairly clear pattern in the way in which the interviewing officer dealt with the complainant's distress, and both were unlike the sympathetic response shown by Jill's friend Kerry, and much more like the institutional responses documented by Hepburn and Potter (2007) and Ruusuvuori (2007).

What the police interviewer did, roughly speaking, was to acknowledge complainants' difficulty in continuing; and that only gave way to an explicit reference to their emotional state if the problem persisted. And in cases where distress had already been acknowledged in one of those ways, acknowledgement was withheld if the complainant expressed distress again.. The analysis of examples below will flesh out the details.

\section{Graded responses if complainants' distress persist within a spate of talk.}

Where the complainant's expressed distress seemed apparently to prevent a return to the action in hand (responding to questions, continuing a narrative), the interviewer's response began with an acknowledgement of difficulty, and escalated to a more empathic response - that is, one that explicitly recognised the emotions that were being displayed - until the current action was reinstated. In Example 4, the complainant has just begun her open narrative account and is quickly overwhelmed by emotion. The interviewer begins receipting this distress at line 9.

Extract 5. INT1 Bus stop. Note that the sign indicates "wobbly voice" 


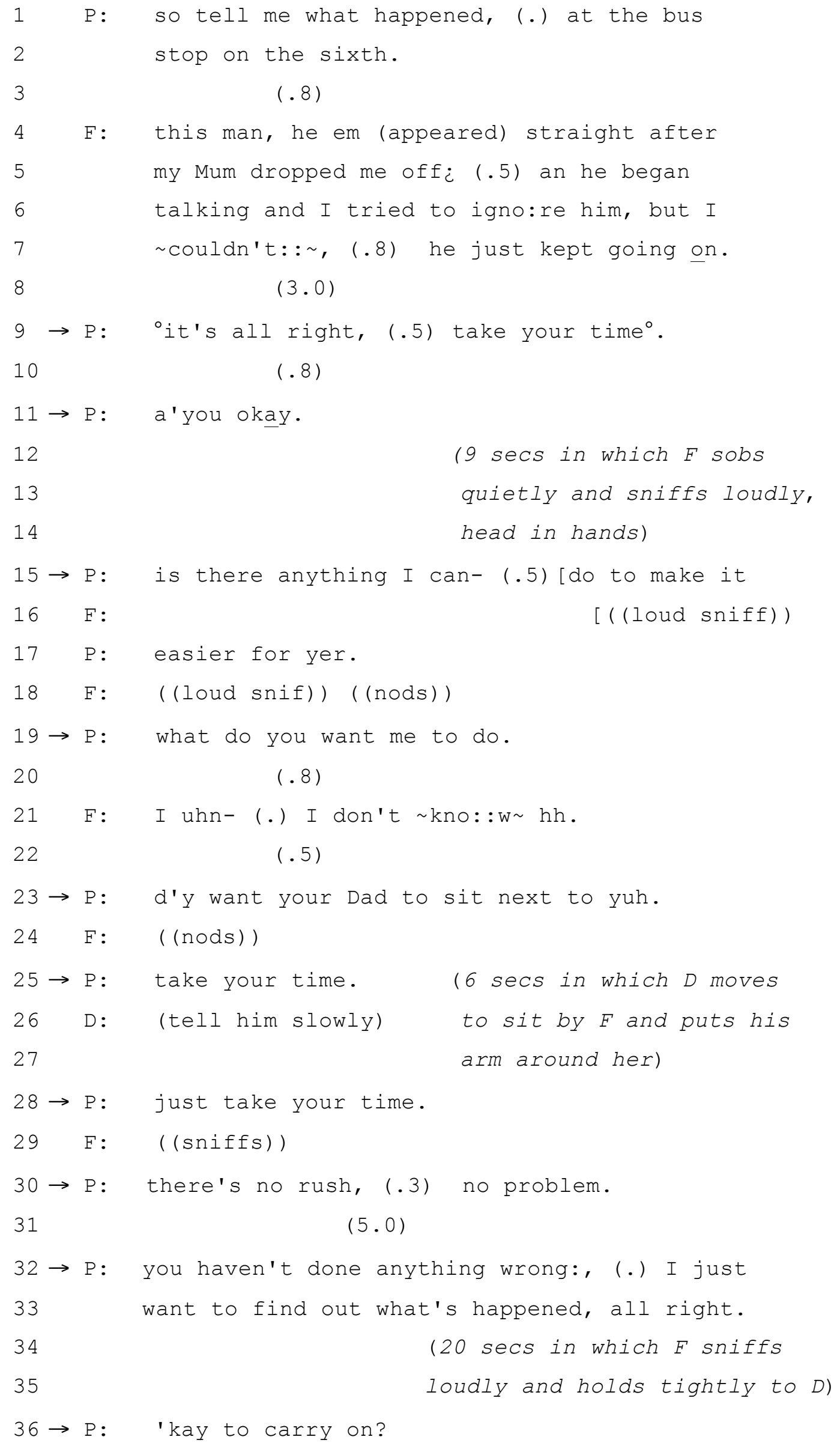




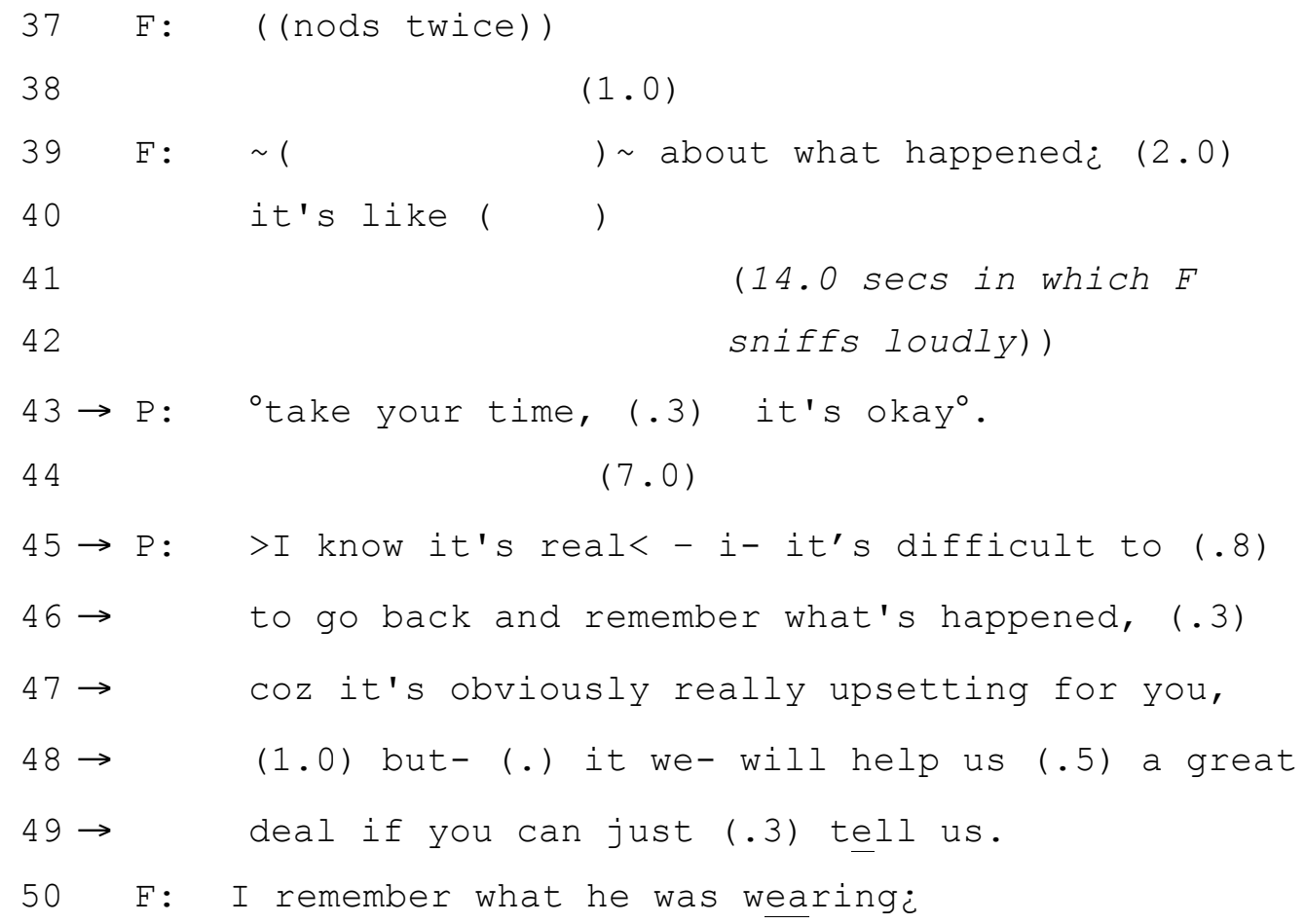

Note the interviewer's graded responses at the arrowed lines: although they acknowledge that there is something amiss, they do not at first explicitly empathise with the complainant's distress as a felt emotion; that is to say, the first responses acknowledge that the complainant is experiencing something that is impeding the onward trajectory of the interview. As Hepburn and Potter (2007) put it in their account of how NSPCC call-takers use the phrase take your time, the phrase seems to be deployed to acknowledge, and licence, a break in talk to be heard as a "response to sequences of crying that involve abnormally long delays combined with disrupted or incomplete TCUs [turn-constructional units" (2007, p 98). Only as the emotion continues, however, and after many noncommittal acknowledgements, does the officer ultimately explicitly recognise the distress with the observation that "it's obviously really upsetting for you". But note that use of "obviously" distances the officer from the implication that she was empathetically interpreting what she was seeing - it is cast as a public fact, implicitly requiring no personal investment in understanding.

In extract 6, again we see that the interviewer's first responses to the complainant's expressed distress is to treat it as a difficulty in proceeding. 


\section{Extract 6 INT3 - Pinned me up against the wall.}

1 F: I went into the bathroom to go to the toilet

2 and that's when he followed me in.

$3 \quad(0.6)$

4 P: okay. An' what happened when he's followed

5 you in.

$6 \quad(0.4)$

7 F: (he pih-) ((gulps and sobs))

$8 \rightarrow \mathrm{P}:$ I know it's really difficult, [I know-

$9 \mathrm{~F}: \quad[($ wails $))$

$10 \rightarrow \mathrm{P}: \quad$ I know you're struggling to [talk about it.]

$11 \mathrm{~F}: \quad$ [gulps]

$12 \mathrm{~F}: \quad(($ sobs $))$

$14 \mathrm{~F}$ : he pinned me up the wall and ra:ped me .

15 ((wails for 2 secs) $)$

16 P : ${ }^{\circ} \mathrm{okay}^{\circ}$.

$17 \quad(3.5)$

18 F: ((wails for 1 sec)

$19 \quad(1.5)$

$20 \quad \mathrm{~F}: \quad \mathrm{HHHH}$

22 F: he grabbed me by me a:rms, (.) hh (1.0)

23 and then he pinned me up to the cupboard

24 that's in the toilet, (5.5) and then he

25 raped me, and then he got off (.5) and then

26 'e just left, like nothing had happenedi

$(2.0)$

28 P: ${ }^{\circ} \mathrm{okay}^{\circ}$.

$29 \quad(2.0)$

30 P: $\quad$ what I'm gonn do<, (name), I know it-

$31 \rightarrow \quad$ it's upsetting you, but ri- it is obviously

$32 \rightarrow \quad$ important that I do need to understand, exactly

33 what has happened.

$34 \quad F: \quad((\operatorname{sniff})))$ 
35 P: I just want to talk about, (.5) from the time

36 you've gone into the bathroom, okay.

Although the interviewer does acknowledge the complainant's distress, it is initially in terms of its hindering her answering the question (lines 8 and 10), and only after continued distress does she explicitly acknowledge the memory being "upsetting" (line 31). Once again, however, this upset is "known" which, like "obviously" in Extract 3 above, implies a more abstract appreciation of what the complainant is going through, rather than full emotional empathy.

\section{Distress acknowledged only as difficulty in proceeding}

More often than the escalation described above, a minimal, or non-emotionimplicative, acknowledgment would not be escalated if the complainant resumed the activity that they had been pursuing before displaying distress.

In Extract 7, the complainant is being asked to give more detail about what her father did to her as a child, and the question turns to an incident in her bed:

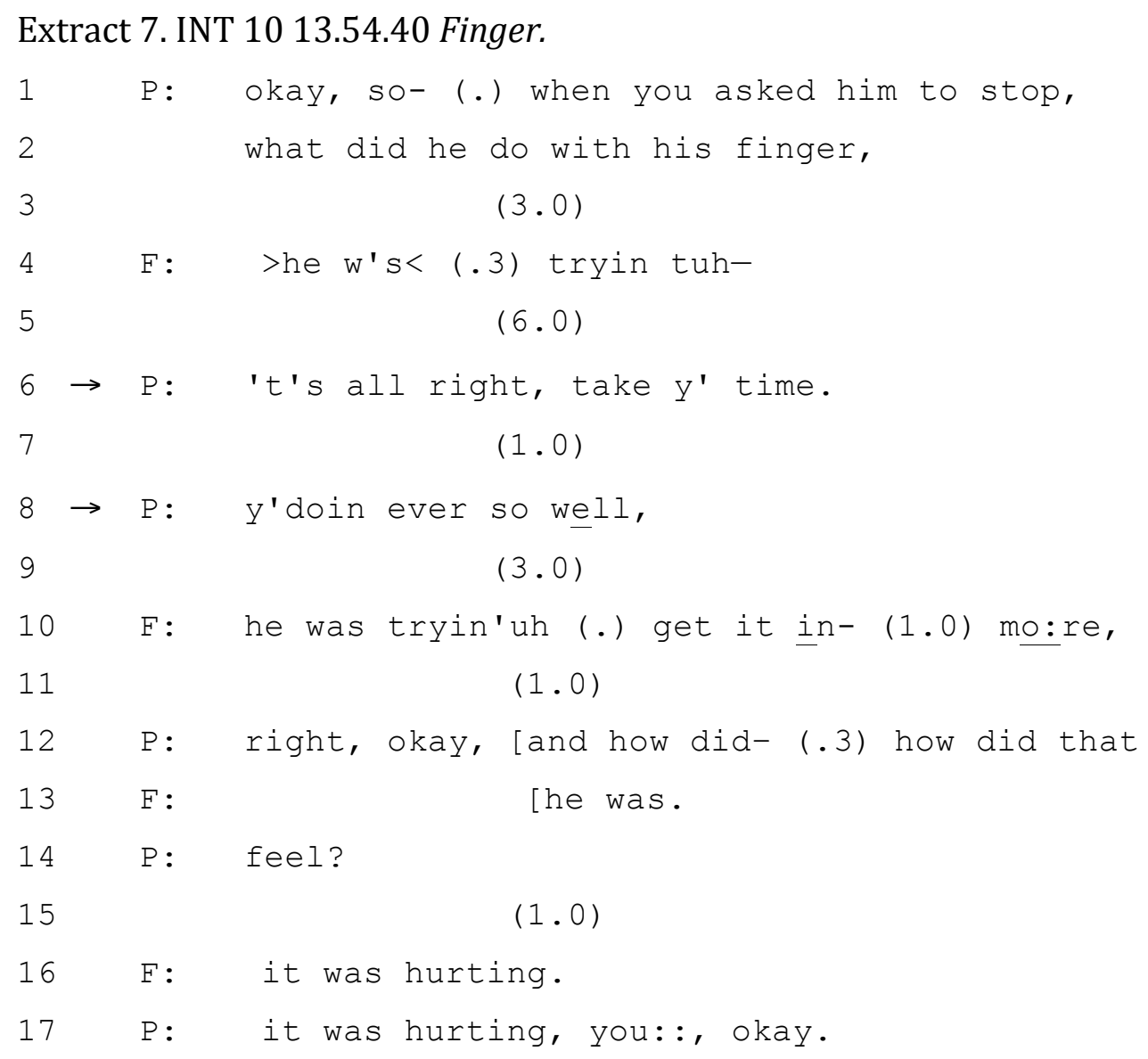




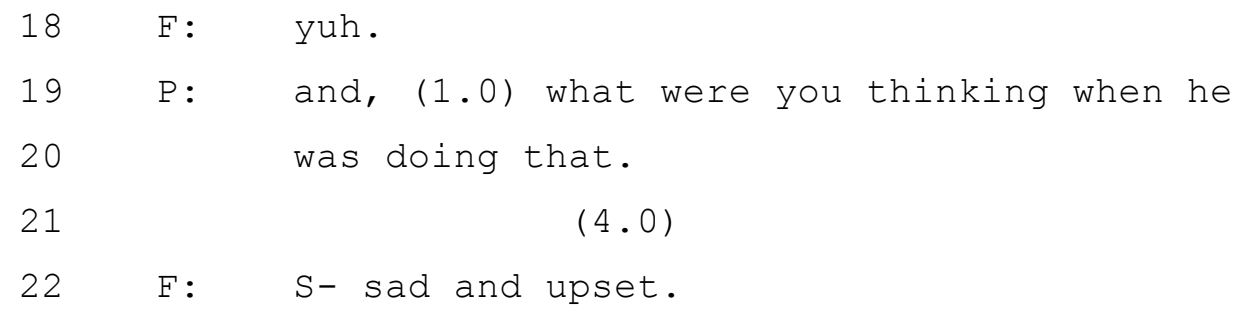

At line 4 the complainant abandons her turn and there are six seconds of silence. She is not audibly crying or visibly moved, nor is her facial expression (somewhat blurred by the anonymisation of the video) distinctly distressed. Nevertheless the abrupt end of her turn, and the especially graphic nature of what she is describing, seems to suggest to the interviewer that she is indeed upset. She handles this by treating the matter as requiring effort and time - not by allusion to the complainant's emotional state as such.

\section{Distress met with minimal or no acknowledgement}

The last practice of dealing with expressed distress that we identified was for the officer to treat it with no mark of empathy: to receipt it only with a minimal, or no, acknowledgement, and to allow, or expect, the complainant to resume the description that they had in train.

In the extract below, the complainant's marked inbreath and outbreath at line 8 and at 17 represents what on the video we would gloss as 'stifled sobbing', and the 'wobbly voice' at line 10 indicates a display of strong emotion held in check.

\section{Extract 8. INT3 Smug look.}

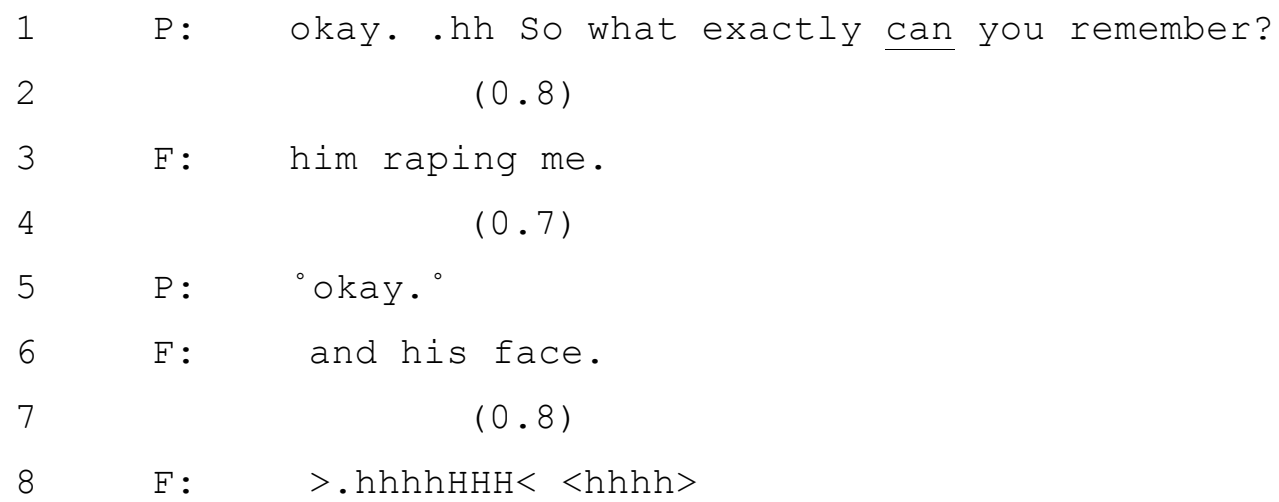




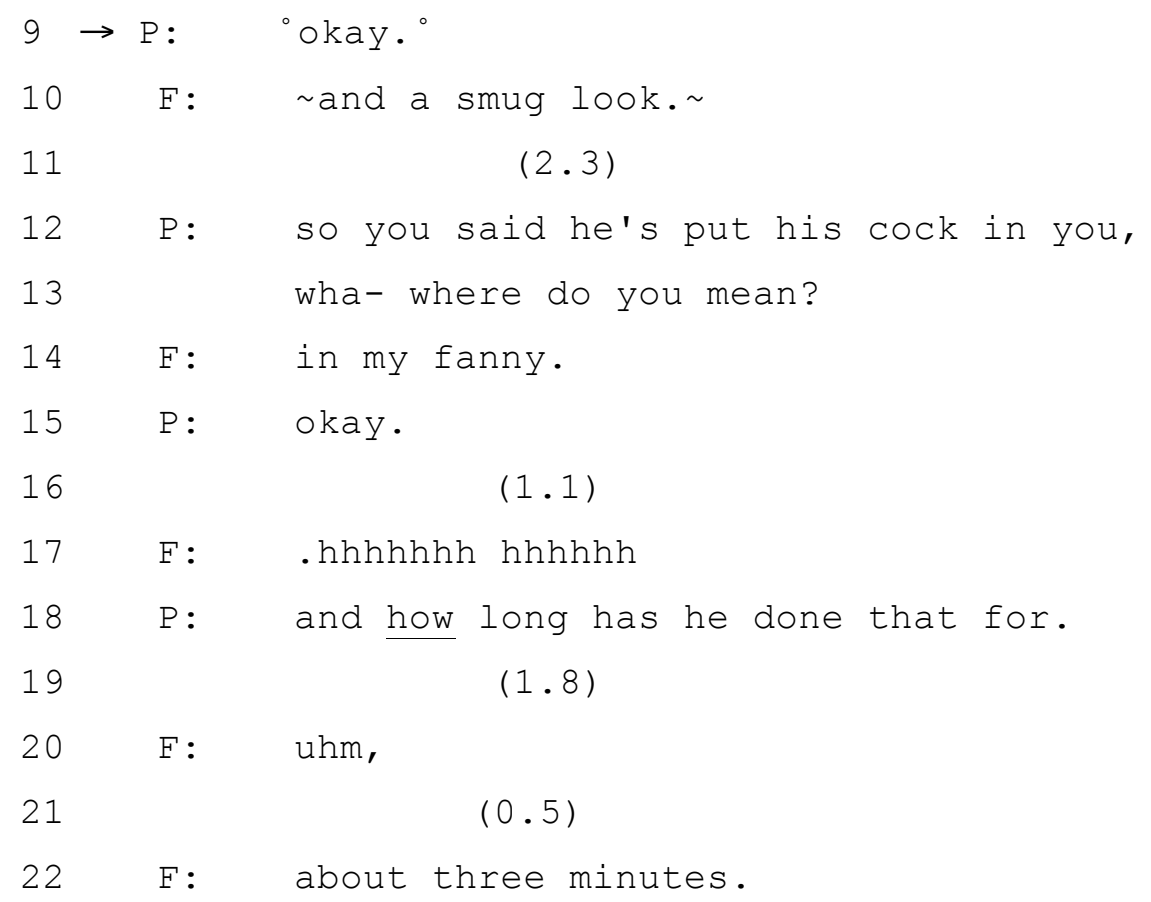

The interviewer receipts the first of these expressions minimally (okay in line 9) but the subsequent ones not at all. Over two seconds pass before, in line 12, she gets 'back on track' (Antaki and Jahoda, 2010) by a so-formulation which deletes the complainant's term 'rape' and replaces it with the more neutral "put his cock in you". In dealing with the complainant's third expression of distress at line 17 she issues a 'follow-up' question (Romaniuk, 2013) in line 18 without further ado.

One case out of the 19 was notable for the almost complete lack of recognition by the police interviewer of the distress manifested by the complainant. The extracts below give a sense of the way in which the complainant expressed his distress (which we can gloss as snuffling, chest heaving, and marked voice quality). Only once is this even minimally acknowledged. In Extract 8, at the start of the interview, the officer is instructing the complainant about the importance of telling the truth (this is mandated by the guidelines that the officer works to, but may be exacerbated by the perceived deficits of the interviewee; see Williams, 2013, pp 41-ff on the mistrust of reports from people with ID). At lines 15-17, the complainant expresses what we might gloss as frustration and despair. 
Extract 9. INT13 16.11.30 Why me.

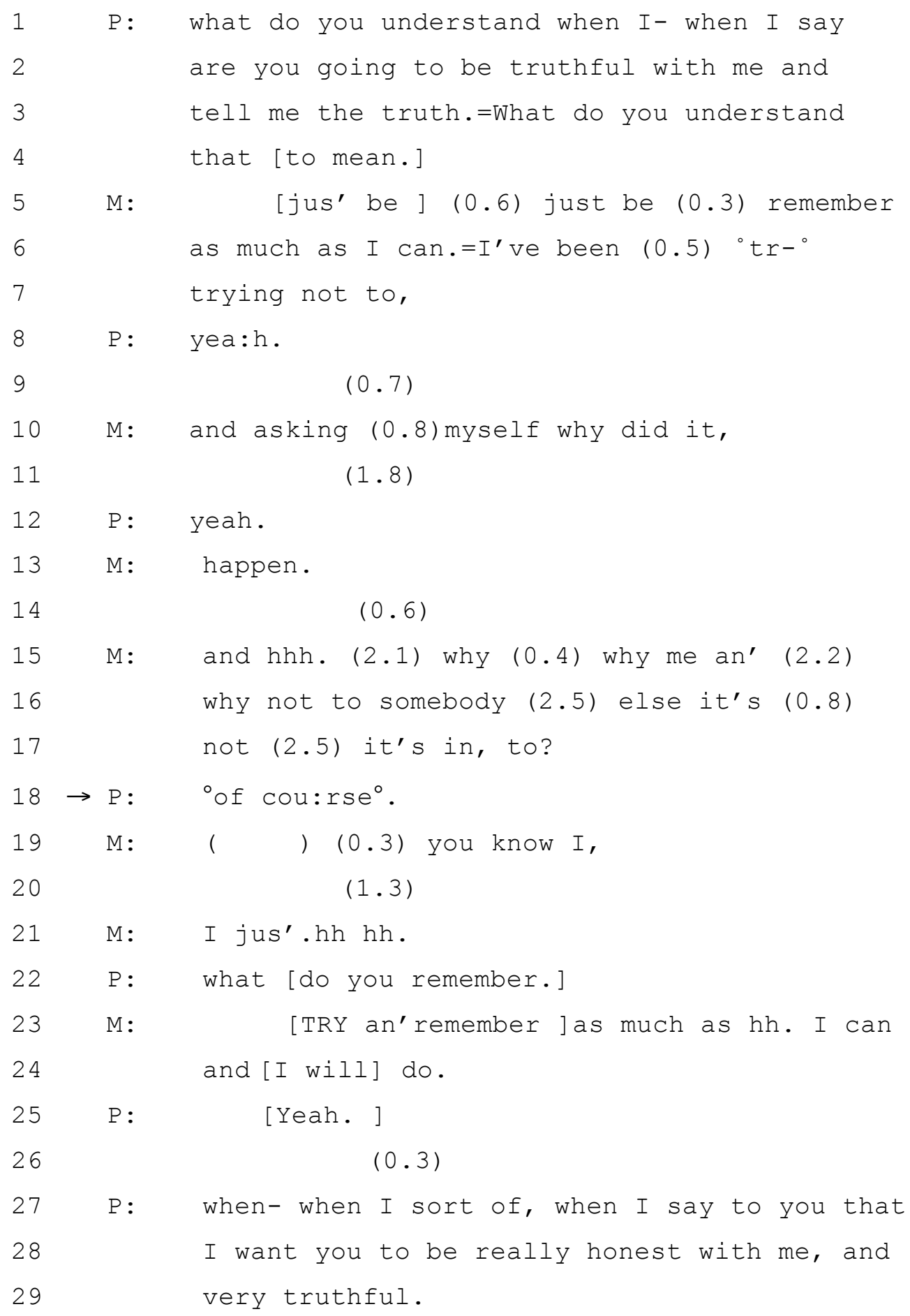

The officer's "of course" in line 18 receipts the complainant's uncompleted announcement (disfluently delivered, with much gulping and chest-heaving) as if confirming something already known (as from a 'knowledge-plus' position, in the terms set out by Heritage, 2012a,b); in this context, it comes across (together 
with its soft delivery, and in its sequential position before the complete termination of the utterance) as reassurance at least that his self-questioning distress is understandable. Thereafter, none of this complainant's similar displays of emotion over the next one and a half hours' interview receive even such minimal responses.

\section{DISCUSSION}

This article set out to examine how police deal with people with intellectual disabilities who approach them alleging sexual assault and rape. The sample of 19 interviews we obtained included people with Down syndrome, autism, and with unspecified "learning disabilities", and who were sometimes challenged by other difficulties such as deafness or physical disability. Prompted by the finding that such vulnerable victims of sexual crime are likely to suffer marked psychological distress (Rowsell, Clare and Murphy 2012, p 257), and conscious that other researchers had found low levels of empathy in environments such as medical consultation (Heritage and Lindström 2012; Ruusuvuori, 2005, 2007) and, most closely to our situation, in calls to a child-abuse helpline (Hepburn and Potter, 2007), our interest was in seeing how the police dealt with the distress that might arise in the interview that they must necessarily put the complainant through.

A null finding worth mentioning is that there was nothing in the data to suggest that the interviewees were distressed as a consequence of any cognitive difficulties they experienced in either understanding the interviewer's questions or in articulating a response to them. This is perhaps testament to the care with which the interviewers approached their task and designed their questions. But most reported having felt very negative emotions (fear, disgust, pain) at the time of the alleged events, or reported having strong feelings about the events, or the alleged perpetrator now (unclean-ness, hatred); and some displayed visible distress in the telling. 
Our first finding is that complainants' reports of distress were routinely not topicalised, and sometimes indeed not explicitly acknowledged. Extracts 1, 2 and 3 were example of cases in which the complainant reported what they felt at the time, or what they currently felt in the sense of a general assessement of their stance towards the event or the perpetrator. Neither of these classes of report prompted a response from the interviewer. Our analysis, following the distinction made by Lindström and Sorjonen (2013) is that the officer was aligning with the complainant's action in story telling, while withholding affiliation to the stance that the story was expressing. This is consistent with other institutional interviews where clients may report troubles: indeed Ruusuvuori reports that "the most usual reception of the patients' troubles tellings was a minimal acknowledgment, silence, and/or a continuation of the task- related activity at hand, such as interviewing the patient $(40 \%$ of the responses in homeopathy, 55\% in general practice consultations)" (Ruusuvuori, 2005, p 208).

What, however, about distress expressed outright? Our main finding was that the interviewer had three ways of handling it. It could be acknowledged minimally (with okay) or not at all; it could be treated as a temporary difficulty, either of effort or memory, or without specification; or, more rarely, it could be recognised for its emotional charge, as Hepburn and Potter (2007) found in in analysing calls to a children's help line. But even in this last receipt, the few occasions on which it occurred showed that the interviewer was careful to acknowledge the emotion as it were intellectually, not empathically (for example by such receipts as I know it's really difficult or you're doin' ever so well). And in one one-and-a-half hour long interview with a man alleging prison rape, the interviewer gave only one, very minimal, response of any kind.

If there is, as Stevanovic and Peräklyä claim (2014), an "emotional order" in talk, which requires a speaker to display a recognition of the emotional stance being expressed by their interlocutor - the kind of response shown by Kerry to her friend Jill in the telephone conversation in example 4 - then it is abeyance here. The explanation for this pattern of dealing with distress is probably to be found 
in the dual, and to some degree conflicting, institutional demands of the interviewing officers' job. Their guidelines require both that they establish rapport with the interviewee, but also that their conduct be seen to be neutral and non-leading - to be, in the words of Achieving Best Evidence, "acceptable to the court". Although our sample of complainants were people with intellectual disabilities, and the findings are possibly exaggerated for that reason, it might well be that this is a general pattern in police interviews with anyone alleging assault; certainly it squares with the critical discourse analysis reported by MacLeod (2010).

Consulting with the police officers with whom we were in contact, we formed the strong impression that for evidence to "be acceptable to the court" effectively meant, amongst other things (such as its audibility, coherence and so on) being seen to be solicited impartially and unjudgmentally. It is here perhaps that the complainant's identity as having an intellectual disability comes most strongly into play, as the officers strive to avoid any hint that they are leading someone who defence counsel may ague will be likely to be suggestible. Part of the interviewer's job is to forestall any accusation by defence counsel that the interviewer had, by being empathic, encouraged a heightened or exaggerated account. This extra contingency, over and above the constraints on such practitioners as medical personnel, health workers and help-line call-takers makes it very difficult for the police officer to do more than - at best acknowledge that the complainant is experiencing something that is interfering with the telling of their story; it favours, as it institutionally is obliged to, forensic probity over empathy. 


\section{References}

Antaki, C, and Jahoda, A. (2010) Psychotherapists' practices in keeping a session "on-track" in the face of clients' "off-track" talk. Communication and Medicine, 7, 11-21

Clare, I. C. H. and Gudjonsson, G. H. (1993) Interrogative suggestibility, confabulation, and acquiescence in people with mild learning disabilities (mental handicap): implications for reliability during police interrogations. British Journal of Clinical Psychology, 32, 295-301

Curl, T S., \& Drew, P (2008) 'Contingency and action: a comparison of two forms of requesting', Research on Language \& Social Interaction, 41, 129-53

Drew, P. , Toerien, M, Irvine, A and Sainsbury, R (2014) Personal Adviser Interviews with Benefits Claimants in UK Jobcentres. Research on Language and Social Interaction, 47, 306-316

Driessen, J.J. (1997) 'Worldly interpretations of a suspicious story', Ethnographic Studies 2:3-15.

Goodwin, M. H., Cekaite, A., Goodwin, C., and Tulbert, E (2012) 'Emotion as stance'. In A. Peräkylä, M.-L. Sorjonen, eds., Emotion in interaction. New York: Oxford University Press: 16-41

Hepburn, A (2004) Crying: notes on description, transcription and interaction. Research on Language and Social Interaction, 37, 251-290

Hepburn, A. \& Potter, J (2007) Crying receipts: time, empathy, and institutional practice, Research on Language and Social Interaction, 40, 89-116

Hepburn, A. \& Potter, J (2014) Crying and crying responses. In A Peräkylä and M-L Sorjonen (eds.) Emotion in Interaction Oxford: Oxford University Press, 195-211

Hepburn, A., Wilkinson, S and Butler, C. W. (2014). Intervening with Conversation Analysis in Telephone Helpline Services: Strategies to Improve Effectiveness. Research on Language and Social Interaction, 47, 239-254

Heritage, John (1984) 'A change-of-state token and aspects of its sequential placement'. In: Atkinson, J. Maxwell, John Heritage, eds. Structures of 
Social Action: Studies in Conversation Analysis. Cambridge: Cambridge University Press: 299-345

Heritage, John (2012a) 'Epistemics in action: action formation and territories of knowledge', Research on Language \& Social Interaction 45/1: 1-29

Heritage, John (2012b) 'The epistemic engine: Sequence organization and territories of knowledge', Research on Language \& Social Interaction 45/1: $30-52$

Heritage, J \& Anna Lindström (2012) 'Knowledge, empathy and emotion in a medical encounter'. In Anssi Peräkylä, Marja-Leena Sorjonen, eds) Emotion in Interaction. Oxford: Oxford University Press: 256-273

Lea, S., Lanvers, U. \& Shaw, S. (2003) Attrition in Rape Cases: Developing a Profile and Identifying Relevant Factors, British Journal of Criminology, 43, 58399.

McEachern, A. G. (2012). Sexual abuse of individuals with disabilities: Prevention strategies for clinical practice. Journal of Child Sexual Abuse, 21(4), 386398 ,

Lindström, A and Sorjonen, M-L (2013) Affiliation in Conversation. In J Sidnell and T Stivers Handbook of Conversation Analysis, Chichester: John Wiley

MacLeod, N J (2010). Police Interviews with Women Reporting Rape: A Critical Discourse Analysis. Birmingham: Aston University, unpublished $\mathrm{PhD}$ thesis

Maynard, D and Heritage, J (2005) Conversation Analysis, doctor-patient interaction and medical communication. Medical Education, 39, 428-435.

Park, Y (2014) The Roles of Third-Turn Repeats in Two L2 Classroom Interactional Contexts. Applied Linguistics, 35, 145-167

Petersilia J R. 2001 Crime Victims with Developmental Disabilities: A Review Essay. Criminal Justice and Behavior 28: 655-694

Pudlinski, Christopher (2005) 'Doing empathy and sympathy: caring responses to troubles tellings on a peer support line', Discourse Studies 7: 267-88 Robinson, J. D. \& Heritage, J., (2014). Intervening with Conversation Analysis: The Case of Medicine. Research on Language and Social Interaction, 47, 201-218 
Rowsell WL, Clare ICH and Murphy G (2012) The psychological impact of abuse on men and women with severe intellectual disabilities. Journal of Applied Research in Intellectual Disabilities, 26: 257-270.

Romaniuk, T. (2013) Pursuing answers to questions in broadcast journalism. Research on Language and Social Interaction, 46, pp 144-164

Royal College of Psychiatrists (2014). Forensic care pathways for adults with intellectual disability involved with the criminal justice system. London: Royal College of Psychiatrists

Ruusuvuori, J. (2005) "Empathy" and "sympathy" in action: Attending to patients' troubles in Finnish homeopathic and general practice consultations, Social Psychology Quarterly 68, 204-222

Ruusuvuori, J. (2007) Managing affect: integration of empathy and problemsolving in healthcare encounters, Discourse Studies 9, 597-622

Stevanovic, M. \& Peräkylä, A. (2014) Three orders in the organization of human action and social relations: On the interface between knowledge, power, and emotion in interaction. Language in Society 43, 185-207

Stokoe, E H (2014) The Conversation-Analytic Role-Play Method (CARM): a method for training communication skills as an alternative to simulated role-play. Research on Language and Social Interaction, 47, 255-264

Sidnell, J. \& Stivers, T. (Eds.) (2012) The Handbook of Conversation Analysis. Chichester: Blackwell-Wiley.

UK Ministry of Justice (2011) Achieving Best Evidence in Criminal Proceedings: Guidance on interviewing victims and witnesses, and guidance on using special measures. London: HMSO http://www.justice.gov.uk/downloads/victims-andwitnesses/vulnerable-witnesses/achieving-best-evidence-criminalproceedings.pdf [accessed June 2014]

Wilkinson, R (2014). Conversation Analysis and intervention in speech and language therapy: Improving aphasic conversation Research on Language and Social Interaction, 47, 219-238

Williams, V. (2013) Learning disability policy and practice: Changing lives?. Basingstoke: Palgrave Macmillan 
Authors' bios

Charles Antaki is Professor of Language and Social Psychology at Loughborough University, in the Department of Social Sciences. His research interests are in Conversation Analysis, and among his publications is the edited collection Applied Conversation Analysis: Intervention and Change in Institutional Talk (Palgrave Macmillan, 2011).

Emma Richardson, $\mathrm{PhD}$ is Research Associate in the Health and Community Care Research Unit within the Institute of Psychology, Health and Society at the University of Liverpool. Her current research interests are in conversation analysis and mental health policy evaluation.

Elizabeth Stokoe is Professor of Social Interaction in the Department of Social Sciences at Loughborough University, UK. Her current research interests are in conversation analysis, membership categorization, and social interaction in various ordinary and institutional settings. She is the co-author of Discourse and Identity (with Bethan Benwell, Edinburgh University Press, 2006) and co-editor of Conversation and Gender (with Susan Speer, Cambridge University Press, 2011).

Sara Willott is a Clinical Psychologist working in a Community Learning Disability Team employed by Birmingham Community Healthcare NHS Trust. Her clinical work is focused on trauma and abuse. Sara has published discourse analytic research on the social construction of gender identities, power relationships and intersubjective processes. 